This item was submitted to Loughborough's Research Repository by the author.

Items in Figshare are protected by copyright, with all rights reserved, unless otherwise indicated.

\title{
The barriers and consequences of radical innovations: introduction to the
} issue

PLEASE CITE THE PUBLISHED VERSION

http://dx.doi.org/10.1016/j.indmarman.2014.09.001

\section{PUBLISHER}

(c) Elsevier

VERSION

AM (Accepted Manuscript)

\section{PUBLISHER STATEMENT}

This work is made available according to the conditions of the Creative Commons Attribution-NonCommercialNoDerivatives 4.0 International (CC BY-NC-ND 4.0) licence. Full details of this licence are available at: https://creativecommons.org/licenses/by-nc-nd/4.0/

\section{LICENCE}

CC BY-NC-ND 4.0

\section{REPOSITORY RECORD}

Story, Vicky, Kevin Daniels, Judy Zolkiewski, and Andrew R.J. Dainty. 2019. "The Barriers and Consequences of Radical Innovations: Introduction to the Issue". figshare. https://hdl.handle.net/2134/18682. 


\title{
The Barriers and Consequences of Radical Innovations
}

\section{Special Issue Editorial}

\author{
Dr Vicky Story (corresponding author)
}

Associate Professor in Marketing, Nottingham University Business School, Jubilee Campus, Wollaton Road, Nottingham, NG8 1BB, UK; Tel. +44 (0)115 8466192; Email:

Vicky.Story@nottingham.ac.uk

\section{Professor Kevin Daniels}

Professor of Organizational Behaviour, Norwich Business School, University of East Anglia, Norwich Research Park, NR4 7TJ.

Professor Judy Zolkiewski

Professor of Marketing, Manchester Business School, Booth Street West, Manchester, M15 6PB, UK.

\section{Professor Andrew R. J. Dainty}

Professor of Construction Sociology; Director of the Graduate School, School of Civil and Building Engineering, Loughborough University, Loughborough, Leicestershire LE11 3TU, UK 


\section{Biography Page}

Dr. Vicky M. Story is an associate professor of marketing at Nottingham University Business School, The University of Nottingham (UK). Her research interests are in the areas of innovation and marketing strategy, and she has published on these issues in such journals as Journal of Product Innovation Management, Journal of Business Venturing, Industrial Marketing Management, and the International Small Business Journal.

Kevin Daniels is Professor of Organizational Behaviour, Norwich Business School, University of East Anglia. Kevin's research interests relate to the psychological aspects of job design, and in particular how individuals shape and enact their job roles to attain specific goals, such as to provide creative solutions to problems. Kevin has published in a range of management and applied psychology journals including Human Relations, Journal of Applied Psychology, Journal of Management, Journal of Occupational and Organization Psychology, Journal of Organizational Behavior and Organization Studies.

Judy Zolkiewski is a Professor of Marketing at Manchester Business School. Her research interests are focused on understanding business markets, relationships and networks both in the traditional manufacturing and engineering industries and in the evolving business-tobusiness services sector with specific focus on relationship and network dynamics, sustainability, strategy and technology. She has published in Journal of Business Research, European Journal of Marketing, Industrial Marketing Management, Journal of Services Marketing and Journal of Business and Industrial Marketing.

Andrew Dainty is Professor of the Sociology of Construction in the School of Civil and Building Engineering, Loughborough University. His research focuses on the social rules and processes that affect people working as members of project teams and on the processes of innovation and innovation diffusion, particularly within temporary organizations. He has published in journals such as Work, Employment and Society, the Scandinavian Journal of Management, Services Industries Journal and the International Journal of Project Management. 
Final version accepted for Publication

\section{Abstract}

This article introduces the special issue on barriers and consequences of radical innovation (RI). Radical innovation, as distinct from more incremental forms of innovation, is increasingly important for organizations and national economies. However, firms face many challenges and barriers (both internal and external) which hinder their RI efforts, and result in significantly higher failure rates for RIs as compared with other forms of innovation. Individually and collectively, the twelve cross-disciplinary articles in this special issue provide a number of important contributions to the extant knowledge base. While most of the contributions focus on barriers, with a concomitant emphasis on enablers, some insights are also offered into the lesser examined area of consequences, particularly the unintended consequences of RI. The editorial concludes by summarizing key issues and presenting provocations for further research. 


\section{Introduction}

It is well recognized that there are risks and opportunities in the exploitation of radical innovation (RI) and the ability of organizations to respond to or address these risks and opportunities may have a significant impact on their ability to exploit the benefits of RI (O'Connor and Ayers, 2005; Slater, Mohr and Sengupta, 2014; Story et al., 2011). Given the centrality of RI to the discourse surrounding growth, sustainability, and competitive advantage (c.f. Kim and Mauborgne, 2005; Tellis, Prabhu and Chandy, 2009), it is surprising that comparatively less attention has been paid to RI than other forms of innovation (in particular, incremental innovation). What is also clear from extant literature is that innovation researchers underpin their research by drawing on and combining diverse theoretical perspectives (Cuevas-Rodriguez, Cabello-Medina and Carmona-Lavado, 2014), including the resource-based view of the firm (Barney, 1991), core competences theory (Prahalad and Hamel, 1990) and social identity theory (Tajfel \& Turner, 1979).

The innovation literature makes a clear distinction between incremental innovations and radical innovations (e.g. Daneels and Kleinschmidt, 2001; Szymanski, Kroff and Troy, 2007; Page and Schirr, 2008), which are likely to have a much more dramatic effect on the marketplace (Rubera and Kirca, 2012; Srinivasan, et al.; 2002 Tellis, et. al. 2009). However, research does not always discriminate clearly between these two (Slater et al., 2014), and this distinction is made more difficult because innovation is generally recognized as a continuum from incremental revisions through to new-to-the world products (Tellis et al., 2009; Avlonitis and Salavou, 2007). Thus, it is not always simple to actually pinpoint what is, or is not a radical innovation, particularly given the differences in terminology and definitions that abound in the extant literature (see Garcia and Calantone (2002) for a comprehensive review of these definitions). Radicalness can also been seen from a number of dimensions, with many RI definitions focusing on 'radical' in terms of the consequences on the market, while others articulate 'radical' being about departure from the prevailing design norms; the supersession of current technologies (Dosi, 1982). That said, definitions are beginning to coalesce around the notion that an innovation is radical if it has unprecedented improvements in performance features that allow for new application domains to develop (e.g. Colarelli-O'Connor and Rice, 2013; Story, O'Malley and Hart, 2011). This implicitly captures the notion of design norms in that 'unprecedented' improvements 
tend only to be possible with departures from current design trajectories, which explicitly captures the market-based dimension of RI's consequences.

Efforts to provide a clear definition are important because extant literature points to the fact that developing RI requires different skills and competences than are necessary for more incremental innovation (Leifer et al., 2000; Holahan, Sullivan \& Markham, 2014). Radical forms of innovation differ by virtue of being inherently more risky and complex than other less radical innovations, typically require greater capital investment, and in that they have much more uncertain market responses (O'Connor and Ayers, 2005; Kock et al., 2011). They are also more likely to manifest through business-to-business markets (Griffin et al. 2013). While some work has been done to understand the implications of these key differences, what is clear is that there is still some way to go to generate the same sort of improvements in success rates as have been seen for incremental innovations (c.f. Colarelli O'Connor and Rice, 2013) and more research is needed to understand the skills, competences and organizational architectures required to improve success rates for these types of innovation activities. More specifically, addressing the risks and opportunities often requires organizations to overcome barriers and how well they do this may have a significant impact on their ability to exploit the benefits of RI.

The introduction of RIs can also lead to some important, but under-researched consequences (particularly unintended consequences, such as changes in practice, people issues etc.). For example, the British agricultural revolution reduced the labor intensity of food production - meaning there was a supply of labor available to divert into manufacturing and employment in factories. Other consequences are more immediate and even less tangible. These are concerned with internal organizational processes and the way managers and others think about and react to innovations.

A second complication stems from the fact that innovation is, by its very nature, interdisciplinary (Cuevas-Rodriguez, Cabello-Medina and Carmona-Lavado, 2014), and while insightful research is being undertaken in a variety of disciplines, - with researchers from such disciplines as engineering, design, economics, sociology, organizational behavior and marketing; there is very little synthesis of this cross-disciplinary research. Therefore, there is a real need to bridge across the different disciplines to open the discourse around the 
issue of RI if we are to generate a better understanding of the barriers to and consequences of more radical forms of innovation. This could lead to the development a multidisciplinary research agenda that will ultimately offer a stronger impact upon policy and practice.

This special issue offered a forum for articles exploring issues of significant academic and managerial interest around the barriers and consequences of $\mathrm{RI}$ in products, services or business processes. These areas are particularly important for academics, policy makers and management practitioners in understanding how to support/foster RI success and what the ultimate consequences can be when business models change as a result of radical innovations. In doing so, the papers also provided a concomitant emphasis on enablers, with many of the contributions offering insights into the ways companies overcome some typical barriers. In the section that follows, we provide an overview of the papers included in the special issue. We conclude the editorial by summarizing the key issues that stand out from these papers and presenting provocations for further research.

\section{Overview of the Articles in the Special Issue}

The 12 papers included in this special issue are a mix of invited and competitive papers that explore and articulate various aspects of RI. All papers were subject to peer review. Collectively, these papers offer insights that progress understanding of RI barriers and enablers, and delineate important consequences for the organizations involved. The papers are grouped into three themes based on their primary focus: framing and synthesis; organizational-level barriers and enablers; and process-oriented insights. There are also important connections to be made across these papers, which we highlight within the next section and then draw together to offer insights/provocations for further research.

\subsection{Framing and Synthesis Papers}

By interrogating generalizations about $\mathrm{RI}$, essential RI innovation processes and extant knowledge of the barriers to $\mathrm{RI}$, the first three papers generate insights that are significant at the macro level. These include a recognition that 'people' are the key for RI, that dealing with discontinuity is problematic, and that the barriers are less related to type of novelty but rather size of firm, target market and development processes phases. 
Starbuck's invited commentary paper "Five stories that illustrate three generalizations about radical innovations" is a thought piece that draws on five cases to illustrate three major themes underpinning $\mathrm{RI}$ - themes that reoccur and are developed in the subsequent papers in this Special Issue. The first theme is that RI is a discovery process that requires action without full understanding of the consequences of action, adaptability to new information, and the ability to deal with constraints and opportunities as they emerge through the process of innovation. The second is that innovators have to prepare and convince internal and external stakeholders (customers, employees, managers) who cling to existing ways of acting and thinking, that the RIs add value: The third is that social interaction has a profound influence (both positive and negative) on RI. Essentially, social interaction can cut both ways. Embeddedness in networks and social capital may stifle or enable $\mathrm{RI}$ - the key is the nature of the social interactions and the climate these interactions engender. Underpinning all three themes are human actions. Starbuck identifies that leaders in particular appear to play an important role in fostering the right actions. Leaders themselves need to be able to adapt: For example through abandoning outdated products, services or processes that they formerly supported; or adapting leadership styles to be hierarchical when crises dictate the exercise of power and egalitarian when subordinates require the psychological safety to challenge the status quo.

Bessant, Öberg and Trifilova's invited paper, "Framing problems in radical innovation", examines the barriers and enablers of three essential innovation processes: search, selection and implementation. Incremental and radical innovation are seen as posing very different challenges and requirements for an organization, and so attempting to do both sets up inevitable tensions in relation to the approaches adopted and the structures which bring them about. Rather than attempt to categorize innovations and the strategies that enable them, the authors explore this as contextually embedded, and the challenge being one of 'framing' innovation. This refers to the establishment of the organizational routines necessary to cope with innovation and, in the case of radical innovation, the discontinuities it inevitably promotes. Transitioning to a new mind-set, or reframing, is both complex and problematic, especially for the existing incumbents who are inevitably locked into existing cognitive frames (see also Hodgkinson and Healey in this special issue). Drawing on the findings of a major international research program they explore this framing of the 
environment and related organizational routines as being located within established zones of exploitation, bounded exploration, extended exploitation and complexity and coevolution, each of which demands different structures, tools and enabling routines for search, selection and implementation. While the enablers for exploitation and exploration are well established, fundamental challenges emerge in relation to the establishment of frames for extended exploitation and complexity and co-evolution. Such a perspective sees the essential problem of RI as not about dealing with novelty per se, but of dealing with the discontinuities that emerge by virtue of needing to operate outside of an established cognitive frame (cf. Starbuck's theme of discovery).

Sandberg and Aarikka-Stenroos in their article, "What makes it so difficult? A systematic review on barriers to radical innovation", offer a comprehensive review and classification of RI barriers identified in extant literature. They identify 103 articles focused on RI barriers and classify these into six main barriers, split between external and internal focus. The first internal barrier is a 'restrictive mindset', which is discussed in Starbuck's and Hodgkinson and Healey's articles. They also identify a 'lack of important innovation competences': being unable to discover new ideas; difficulties in incubating good ideas; difficulties of moving ideas from the incubation phase to acceleration phase, which is also picked up in Griffin, Price, Vojak and Hoffmann's article, when they discuss 'the valley of death' and explored in more depth by Aarikka-Stenroos and Lehtimäki in terms of the ability to launch a successful product. The third barrier identified is 'insufficient resources'. Developing radical innovations is more costly, than developing incremental innovation (e.g. Sorescu et al., 2003), and so, any increases in RI efforts will create resourcing issues for firms. However, other recent work (Keupp and Gassmann, 2013: 1457) highlights a conflict in research findings regarding resources, arguing that some work shows that RIs "can be developed efficiently despite - or even because of - resource constraints". What is also clear is that firms have problems balancing current and future business models (the well-recognized exploration/exploitation argument) and this may be exacerbated by the fourth barrier, which is 'unsupportive organizational structures'. This point is echoed in Reid, de Brentani and Kleinschmidt.

In the external barriers identified, the main barrier relates to resistance or lack of support from external actors. The identification of 'customer resistance' as a key external barrier resonates with later papers by with Griffin, Price, Vojak and Hoffmann and Aarikka-Stenroos 
and Lehtimaki, who both offer insights for overcoming this key barrier. The paper by Eggers, Kraus and Covin also illustrates that, in the right circumstances, involving customers can enable RI. It is also clear that the macro-environment culture also influence RI activity, in particular, technological turbulence, underdeveloped networks and ecosystems, and restrictive local cultures. These factors are also explored by O'Malley, O'Dwyer, McNally and Murphy, Eggers, Kraus and Covin, and Baker, Sinkula, Grinstein and Rosenzweig. Interestingly, the evidence presented suggests that degree of novelty did not affect the barriers identified. This suggests that future research may not need to worry so much about exactly what type of RI it is examining, in terms of comparability, as they all suffer from similar barriers. What seems more influential are contextual variables, such as size and target market, and process stage, suggesting specificity is important in these areas.

\subsection{Organizational Barriers and Enablers}

The five papers in this theme focus on organizational structural and cultural barriers and enablers covering the psychological micro-foundations of $\mathrm{Rl}$, the importance of congruence between values and norms, how façades support deviations from current 'root' practices, the development of dual organization identity and how the structural and cultural consequences of a RI can stifle future RI activities. Insights from these papers include: the role of emotion and 'hot' cognitive processes in $\mathrm{RI}$, the relative importance of norms over values and the fact that incongruence is not necessarily a bad thing, the idea that RI can flourish behind even poor innovation façades, and network barriers and enablers.

In their invited paper "Coming in from the Cold: The Psychological micro-foundations of radical innovation revisited" Hodgkinson and Healey critique the micro-foundational basis of practices purporting to address the challenges of RI, positing that the dynamic capabilities required are founded on a combination of reason and emotion. They argue that current understanding is largely based on a cold-cognition perspective of human psychology which has tended to stymie attempts to foster the mind-sets and behavior necessary to overcome the dynamic challenges posed by RI. Drawing insights from neuroeconomics and cognitive neuroscience they challenge the 'cold cognition logic' that underpins much of the innovation discourse. Their analysis suggests that emotional processes may impede RIthrough, for example, emotional attachments to existing social identities coupled tightly 
Final version accepted for Publication

with existing products or processes - but that conversely successful RI is predicated on emotional commitment to the new opportunities, recognizing that emotion and affect are important to the adaptive capabilities required. These are themselves shaped by organizational architectures and support systems that must therefore promote the 'hot' cognitive processes necessary. They develop a research agenda aimed at positioning emotion management at the center of RI.

Baker, Sinkula, Grinstein and Rosenzweig's article, titled "The effect of radical innovation in/congruence on new product performance" examines an understudied construct, 'radical innovation congruence', which is defined as the degree of correspondence between management's RI values - the vision top management endorses - and RI norms - expected behaviors from lower to mid-level employees. Based on a quantitative survey of senior marketing executives, the empirical work examines data from 236 US-based companies. While much research suggests that congruence is important, this work actually identifies that incongruence is not necessarily bad; that RI incongruence can actually positively influence new product performance, but only in situations where norms are higher than values. This finding resonates strongly with the views expressed later in Baumard's 'façades' paper in terms of the positive consequences of incongruence in terms of RI performance outcomes. This also seems to fit with the findings of Reid et al., who note that it is insufficient for firms to simply invest in organizational innovation tools and processes, without also supporting individual-level behaviors that deliver 'out of the box' thinking. The paper also highlights that incongruence can develop as a consequence of entrenched and overly cautious top management. The paper concludes with a number of interesting questions for further research regarding differences in values and norms. In particular, does it matter whether incongruence stems from autonomy or poor communication? What about values and norms in networked organizations? Do findings regarding congruence or incongruence differ when innovation occurs in an ecosystem? Clearly, further work is needed to unpick the mechanisms by which key organizational cultures and structures interact to support RI activities.

Baumard's invited article, "Tearing down the façades of radical innovation" provides an ethnographic, longitudinal real time study of the creation of an organization innovation façade from its initial crafting through to its ultimate collapse. Façades are generally seen as 
a mechanism for 'concealing something inferior' (Nystrom \& Starbuck, 1984: 1). However, this article explores an alternative perspective of 'façades' as mechanisms that have an important role in triggering, fostering and enforcing $\mathrm{RI}$ - enabling firms to deviate from current root practices. The paper shows the social complexity of RI and illustrates that, in this case, RI occurred through a series of social and organizational processes that proceeded in an incremental, but not necessarily planned or linear fashion. Indeed, it is clear from the case that many of the changes were somewhat unintentional, but allowed an environment for RI to occur unhindered. The groups studied (e.g., engineers) used various social processes (façade construction) to evade control of other stakeholders (e.g., owners, managers) to pursue their own interests and the façade that was crafted allowed spaces to develop that supported the emergence and development of radical ideas. This work complements the ideas presented in Bessant, Öberg and Trifilova in terms of how firms might transition to a new mind-set. Interestingly, the prima facie powerful stakeholders (e.g., managers), through constructing and maintaining their own façades, accessed resources and avoided control by others (particularly the parent organization), which benefited everyone (particularly the engineers, who recognized that the progressive façade was giving them more resources). However, in order to take advantage of these additional resources, engineers had to develop their own 'micro-façades' and it was the interaction between the managers' and engineers' façades that created spaces for RI to flourish.

What is also clear from this case is that façades have a precarious and evolving existence. Any vision, by its very nature, is precarious and evolving, because it is focused on an uncertain future, clearly then, a façade will only survive as long as it provides appropriate space behind to achieve the vision it represents. The case studied by Baumard also exemplifies the kinds of problems that occur when top managers do not then know how to achieve the vision that they have carefully crafted through their façade.

O'Malley, O'Dwyer, McNally and Murphy's paper is entitled "Identity, Collaboration and Radical Innovation: The Role of Dual Organization Identification". The authors explore a relatively under-researched topic, that of dual organization identity, and how this affects RI processes, and the RI effects that emerge. This is particularly salient in the context of networks and clusters, where it could be suggested that this effect is most prominent in managed networks rather than those that emerge organically. Their empirical context is a 
collaborative network instigated through the Irish Development Agency with the remit of moving their pharmaceutical industry from manufacturing to a research and development base. Here it becomes clear that for RI to be successful network members (actors) need to be able to identify with both their own organization and the collaborative network. This resonates with themes identified in other papers in this special issue, i.e. the barriers to RI (Sandberg \& Aarikka-Stenroos), with restrictive mind-sets and a desire to retain existing ways of working (highlighted by both Starbuck and Hodgkinson and Healey) and macroenvironmental culture being seen as inhibitors the success of RI in this context. The empirical findings also illustrate how organizations can learn to collaborate in order to successfully develop radical innovations and that regional initiatives have been successful in facilitating this. It is the only paper to explicitly consider network effects and how they influence RI, suggesting that assuming a network identity is a key and necessary success factor.

Green and Cluley, in their competitive paper "The field of radical innovation: making sense of organizational cultures and radical innovation", illustrate, in an SME context, how the consequences of RI may in fact stifle the essence of creativity that spawned the original RI. Green and Cluley bring a new perspective to the study of the internal dynamics that emanate from the successful commercialization of a RI by using Bourdieu's notion of fields to explain how the changes in roles, structures and organizational culture and dynamics that result from successful innovation have consequences for how the SME is able to manage its success and its future ability to innovate. This is exemplified by a change in organizational culture from organic to mechanistic and separated despite the owners' attempts to maintain the organization's organic nature; their change in role has impacted on the culture and they appear powerless to return it to its previous state. It is possible that the change in culture produces a barrier to future RI. There is, however, potentially some connection with Baker, Sinkula, Grinstein and Rosenzweig's idea of a firm shifting into RI 'incongruence' as a result of management rigidity. It is perhaps too early to say if the entrepreneurial founders of Truffle are serial innovators (Griffin et al.), especially as they do not appear to be able to overcome the barriers to innovation that seem to be linked to the new organizational routines and processes. There is also a connection to the points made by Hodgkinson and 
Final version accepted for Publication

Healey, as the case of Truffle illustrates how an emotional reaction to a culture change becomes a barrier to further RI.

\subsection{Radical Innovation Processes}

Four papers focus on the process-oriented barriers and enablers for RI, from the fuzzy front end (FFE) to the back-end commercialization stage, as well as the wider interactions between environmental factors and social processes that can synergistically enhance RI. Together they offer insights into how to overcome key process barriers related to breaking out of the current frame, transitioning RIs over the valley of death, successfully commercializing Rls through careful and proactive development of the market, and the importance of wider networks in the development of RIs.

Reid, de Brentani and Kleinschmidt's invited paper, titled "Divergent thinking and market visioning competence: An early front-end radical innovation success typology", focuses on identifying the conditions that foster the development of an effective Market Visioning Competence (MVC) - the ability to link advanced technologies to market opportunities of the future and how it supports RI by enabling the firm to think outside existing frames of reference that typically skew firm innovation portfolios towards incremental innovation. They study four antecedents: two individual-level constructs, 'divergent thinking attitude' and 'ideation behavior'; and two organizational-level firm culture antecedents, 'idea freedom' and 'diversity'. MVC comprises individual-level capabilities ('networking' and 'ideadriving'); and organizational-level capabilities 'market learning tools' and 'proactive market orientation') that they argue enable a firm to develop and articulate a clear Market Vision (MV), around which the firm's efforts can coalesce.

Using a sample of 198 high-tech nanotechnology sector firms based in North America, the authors identify three distinct firm profile clusters. Profile one is termed the "balanced MVC profile', which the authors argue is a 'model' for managers who are attempting to develop an effective MVC, based on the significantly higher performance outcome scores when compared to the other two groups. The other two clusters are then seen to be less effective in terms of performance outcomes. Cluster 2, called 'Need MVC System/Culture', is seen to have a number of important individual-level building blocks in place for effective MVC, but lacks organizational-level factors. The final cluster, labelled 'Lack MVC Basics', highlights 
firms that have invested in infrastructure but have neglected individual-level competences. This suggests that developing individual capabilities, e.g. through hiring the right people, with the capacity to think outside the current reference frame, is necessary but insufficient to be successful without the wider organizational-level factors, such as infrastructural tools and systems, that support, encourage and nurture this divergent thinking.

This resonates with the findings of the next paper on serial innovators, who have strong individual-level capabilities but require an organizational context that supports their activities. The paper also offers ideas for how to overcome the 'framing' barriers identified within the Bessant, Öberg and Trifilova paper and provides insights into how to develop a stronger 'innovation' competence - a key barrier identified in the Sandberg and AarikkaStenroos paper.

Griffin, Price, Vojak and Hoffmann, in their invited paper, "Serial innovators' processes: How they overcome barriers to creating radical innovations", identify a number of barriers to innovation that can specifically be overcome through the processes developed by 'serial innovators'. These serial innovators, working in larger organizations, have been responsible for the successful commercialization of multiple RIs during their career. In particular, what is interesting are the processes they put in place to overcome key barriers to RI. Specifically, how they focus their efforts on interesting problems, as opposed to more typical technology-push efforts, and focus a significant amount of effort and time understanding the problem; how they support and explicitly manage the transition from the fuzzy front end tasks to the more formal development processes to overcome problems related to the valley of death; and how proactive they are in terms of creating market acceptance, moving from acceleration through to full commercialization. These individuals are clearly politically astute, able to 'run interference' within the organization to overcome any potential obstacles that are put in the way, obtain necessary resources and drive their project through. They are also socially capable individuals, able to engage in discussions with engineers, top managers, marketing and even customers. This idea resonates with the findings presented by Baumard on 'Façade crafting' and the ability of façades to build buffers for resources that require a temporary institutional 'hide out' to give them more time to develop. Griffin, Price, Vojak and Hoffmann also articulate the importance of having an appropriate structure and reporting mechanisms that allow these individuals to move 
between functions, engage in both the typically separate FFE activities as well as the more formal innovation process activities necessary to bring a RI to market, and be flexible enough to allow them to tap into additional resources as the process requires. The freedom that they gain from operating within, but also slightly outside the firm structure allows them more flexibility to go round a loop often enough to ensure that a good idea is generated, which seems to both speed up the process down the line and improve the likelihood that the idea will successfully commercialize. This focus on developing a clear idea is consistent with Reid, de Brentani and Kleinschmidt's assertions regarding the importance of Market Visioning.

In their competitive article, "Commercializing a radical innovation: probing the way to the market" Aarikka-Stenroos and Lehtimaki use data from six longitudinal case studies to develop a detailed process model of the commercialization stage that captures the dynamic nature of the key commercialization activities.

In line with Starbuck and Griffin et al., Aarikka-Stenroos and Lehtimaki argue that the innovation process for radical innovations tends to be a non-linear, probing process rather than a linear process of wisely predetermined decisions. Hence, their focus on understanding the dynamic nature of the commercialization process and the factors that hinder or support the launch of RIs. By focusing specifically on the launch phase, they offer important insights into a critical, but currently less understood, aspect of the RI process.

Within the model developed they identify three distinct zones of activity: strategic decisionmaking; market creation and preparation activities; and sales creation and development activities. While their findings inevitably suggest that effort needs to be directed to all three zones to achieve successful sales, they particularly note that the market creation and preparation stage, neglected in a number of cases, was a major reason for failure. We know from other work, that many entrepreneurial firms leap to get their product out into the market hoping for quick returns (Marmer et al., 2012; Skok, 2013), but the findings from Aarikka-Stenroos and Lehtimaki suggest that, even for larger firms, more efforts on market creation and preparation might improve success rates considerably. This is consistent with Bessant et al.'s final remarks related to how approaches like 'lean start-up' (Ries, 2011), which emphasize fast learning around experiments, can be enabled in the context of 
corporate entrepreneurship activities to support the successful commercialization of RIs. There is also a clear connection with Baumard's paper on façades, in that the zigzagging, unpredictable, iterative and interactive process needed to develop RIs, may require façades to be built to support these developments through firm's more rigid, linear structures.

In their paper, "Traveling into unexplored territory: Radical innovativeness and the role of networking, customers, and technologically turbulent environments", Eggers, Kraus and Covin describe a survey study of small and medium sized enterprises that examines the conditions within which organizational networks promote innovation by examining the interactions between environmental factors and social processes that can synergistically enhance RI. They argue that collaborating with customers can help identify market needs and develop new ideas. Thus, Eggers, Kraus and Covin suggest that the most innovative firms may exhibit high levels of organizational networking and high levels of customer responsiveness. Noting that customer responsiveness might be related to incremental innovation also, they resolve a potential tension between RI and incremental innovation by arguing for environmental turbulence as an additional moderator. Eggers, Kraus and Covin also argue that turbulent environments stimulate RI because turbulent environments require new knowledge to meet new demands and because turbulent environments provide more opportunities to innovate. They find support for their proposed three-way interaction, in that RI was highest in their sample when networking, customer responsiveness, and technological turbulence were concurrently high.

\section{Discussion}

Key to RI seems to be the ability of the firm to break out of thinking that ties them to their current frame. This ability stems not specifically from an ability to think radically, but more from an ability to cope with discontinuity. This process seems to require both sense-making and sense-breaking. Reid, de Brentani and Kleinschmidt identify the importance of being able to develop a clear market vision for new ideas to create 'buy in', Griffin et al.'s 'serial innovators' play an important role in smoothing the effect of these discontinuities and Hodgkinson and Healey highlight the importance of emotional commitment to the new opportunities, recognizing that emotion and affect are important to the adaptive capabilities required. Findings from the O'Malley et al. paper raise an interesting question 
about how necessary sense-breaking might occur, without detrimental effects to individuals or the network, through the development of a duel identity. Interestingly, the work of Green and Cluley seems to suggest that sense-making capabilities developed relating to a specific RI in a small organization appeared to deteriorate once the innovation was successfully commercialized. At this stage, by necessity, management becomes more mechanistic, in order to deal with the consequential growth phase (through the stabilization of routines and focused sales efforts), which impacted on the space needed to continue with the innovative imperative. This suggests that active management is needed to ensure that these sense-making capabilities are not lost or diminished.

Unquestionably, RI requires firms to be adaptable. This ability to adapt seems to stem from both mind-set (c.f. Hodgkinson and Healey), in terms of acceptance and openness to change, and through organizational capabilities (Slater et al., 2014), for example dynamic capabilities (Teece, 2007). But exactly how do firms develop and maintain (a problem highlighted by Green and Cluley) an open mind-set as an organization and exactly how does a firm develop dynamic capabilities? Work on dynamic capabilities has explored 'what they are' (Eisenhardt \& Martin, 2000; Teece, 2007) and Kindström et al. (2013) discuss three key dynamic capabilities in relation to enabling service innovation. However, research now needs to establish exactly how firms develop such dynamic capabilities to exploit RI opportunities while at the same time maintaining balance their innovation activities. These issues remain underexplored in the extant literature.

An interesting point raised in both Starbuck and Baumard that resonates with the wider literature (e.g. Yadav, Prabhu and Chandy, 2007), is that leaders set the tone for innovation. Strategic intent is generally seen as an important driver of innovation (Slater et al., 2014), but in a sense, what is strategic intent, or a 'market vision' but a façade (at least at the time of crafting)? Where firms come unstuck is when top managers are then unable or unwilling to do what is necessary to achieve the vision set. Or, as in the case of Truffle (Green and Cluley paper), the consequences of commercialization seem to stifle the environment that facilitated the RI in the first place. Indeed, many of the papers highlight the importance of a conducive social environment for RI. This can include having an organizational culture that supports individual creativity, as well as being able to access wider relationships with customers and other network partners. In terms of the former, the psychological safety to 
say and do innovative things, with supportive management is clearly important (Starbuck). While this may be engendered by the intentional efforts of management as in the O'Malley et al., paper, it is also possible to create the necessary supportive environment without top management involvement as evidenced by both the Baker et al., and Baumard papers. In the case of Baker et al., behavioral norms were much more important than top management values and in the case of Baumard, engineers gained space to innovate by creating micro-façades to deceive senior managers. On the other hand, O'Malley et al., demonstrate how deliberate action can engender an environment that supports $\mathrm{RI}$ in a network context, where mobilization of group resources results in positive outcomes for all the actors involved.

The importance of wider networks, ecosystems and involvement of stakeholders in overcoming barriers to RI relationships is not, in itself, a surprising finding. Given how resource intense and complex RI projects are, they regularly involve collaboration with network partners (Barczak et al., 2009). However, what is clear from the articles included is that social interaction can clearly cut both ways; by supporting or stifling RI. Furthermore, it is clear from O'Malley et al., that outside stakeholders can also influence RI through supporting the development of regional innovation networks that can have a significant impact on RI potential (see also Eggers et al.). More work needs to be done in this area to understand what relationships support or stifle RI and how firms can benefit from innovation networks and ecosystems.

In terms of process insights, it is interesting to note that while much extant literature has focused on developing formal processes for developing new products to improve the chances of a successful outcome, the work of Griffin et al., and Aarikka-Stenroos and Lehtimaki in this special issue highlight the iterative, fluid nature of the development process for RIs. Importantly, these papers also confirm that the commercialization phase for RIs is inevitably more difficult than for incremental innovations (Slater et al., 2014; Olson et al., 1995). Two key conclusions can be drawn from across these process papers. There is a pressing need to: 1 ) delve further into each of the stages; the phases are complexities have yet to be fully understood; and 2) to understand the dynamics of the process, which is clearly more iterative and fluid than is generally captured in extant literature. This nonlinear process of innovation as a process of iterative experimentation is consistent with 
work in the strategy and entrepreneurial field on 'experimentation' (c.f. Nicholls-Nixon, Cooper and Woo, 2000).

While this special issue has focused on $\mathrm{Rl}$, it is clear from this set of papers that a perennial problem for managers in terms of developing radical innovations is actually about how to balance incremental and RI activities - the explore/exploit dilemma (March, 1991). Explicit and implicit in many of the papers is a tension for $\mathrm{RI}$ that is embedded in decisions relating to how best to manage RI alongside incremental innovation and how firms can avoid becoming trapped by "the blinders of dominant logic" (Prahalad, 2004: 172). Bessant et al., for example, suggest the development of new routines that complement existing ones rather than replace them, such as through the establishment of special incubation units. Griffin et al., explore how firms create room for serial innovators to work within an organization that, necessarily, has to be set up to focus more on the current frame.

\section{Provocations for Future Research}

Together, the contributions of this special issue provide theoretically diverse insights which offer a useful basis for re-thinking the way in which RI is framed, managed and exploited within organizations. They also provide some useful provocations for ensuring that our collective understanding of RI develops in terms of its sophistication, especially in relation to its relationship with other organizational routines and processes. As Starbuck suggests, there are many and varied social and organizational processes that interact and, while unpicking these will be tricky, it is vital if we are to make progress in this area. In this respect, Sandberg and Aarikka-Stenroos' systematic review offers researchers is a mechanism to categorize, target and delve deeper - exploring the specific mechanisms through which these barriers impede RI activities.

Further work is needed to understand the intricacies of the process and boundary conditions for developing radical innovations. However, while there is a good deal of consistency in the findings presented, there is also clear evidence that we now need to further interrogate performance differentials, both between different sized firms and within different sectors in order to appreciate the effect of boundary conditions. This is argued to be necessary in order to meaningfully advance theory (Schilke, 2013; Stam and Elfring, 2008). While this is difficult, it is necessary. Furthermore, research needs to better capture 
the dynamic nature of innovation activities, for example, in terms of processes and relationships over time. Essentially, this work offers a starting point to now flip our focus onto 'enablers' of Rl; how to overcome these barriers.

Bessant, Öberg and Trifilova also provide a way of establishing the zone of innovation concerned, and the reframing requirements which differ in relation to the structures, tools and enabling routines required search, selection and implementation.

Hodgkinson and Healy emphasize the importance of paying attention to the emotional capacities of individuals and groups as well as cognitive aspects. This, in turn, demands a concomitant focus on organizational architectures, systems and processes that promotes the emotional engagement necessary for RI. This idea is also captured in Reid, de Brentani and Kleinschmidt in terms of developing a 'balanced MVC profile' - but what is needed now is an understanding of how a firm can develop this 'balance' through appropriate investment in systems, people and NPD policies? Griffin et al., also raise some interesting points about 'mindset' in terms of how firms can foster the capabilities of serial innovators.

Baker, Sinkula, Grinstein and Rosenzweig raise an important point about how top management can effectively lead, if norms are more important than values for RI. This is echoed within the Green and Cluley article in terms of understanding how changes in organizational structure and culture can inhibit further RI. Following on from this, Baumard's paper raises questions about how clandestine practices that are enacted to protect interference from stakeholders with other goals enable radical innovations to be developed and the level of collusion that is necessary for these façades to succeed.

A key area identified in a number of the papers relates to customers and the wider network and market. O'Malley et al.'s paper suggests the importance of understanding the capabilities needed to capitalize upon the benefits that emerge through accommodating shifts in identity and identification relating to successful collaboration either with a partner or within a network context. While Eggers et al.'s work indicates that it might be useful for research to unpack the situations when customers say 'go for it' and encourage RI versus those in which customers need to be persuaded (cf. Starbuck on marketing ideas). Aarikka- 
Stenroos and Lehtimaki emphasize the need to explore how firms can improve their market preparation and sales creation abilities.

Given that cost and resource constraints are a key issue for $\mathrm{Rl}$, with many of the articles highlighting resource barriers, moving forward more work needs to be done to understand how firms can either reduce these barriers (e.g. through improved networking activities) or find creative ways to overcome them. Work also needs to be done to explore how the practices used to overcome barriers differ between large and small firms, start-ups or notfor-profit firms. Griffin et al., in particular, raise the question of whether serial innovators can operate successfully in other types of organizations, for example, start-ups or non-profit organizations.

The research field would also benefit from some methodological developments. Clearly, some of the calls for future research will require longitudinal research and real time research in order to capture the dynamic nature of RI. They will also require multi-level analysis - individual, group, firm, sector, as well as the examination of cross-level interactions in order to identify which organizational environments and cultures support those individuals with the competencies for RI. Adopting a multi-disciplinary approach, while challenging, might also offer an avenue for stronger theory development.

This special issue offered a platform for exploring both the barriers and consequences of RI. Research has clearly made significant inroads into developing our understanding the barriers and enablers of RI and offered some insights into some interesting unintended consequences. However, further work now needs to be done by the research community to begin to address the challenging calls for future research that have surfaced from this special issue. We hope that the papers presented in this special issue will provoke further research to help develop answers to some of these questions.

\section{Acknowledgements}

We would like to that all those who were involved in the process of producing this special issue. In particular, we are sincerely grateful for all the efforts of the reviewers and acknowledge their contribution in developing this special issue. We would also like to acknowledge the ESRC for providing the funding for the seminar series (Grant title: 
Successful Radical Innovation: From Ideas to Market; Grant reference number: RES-451-260496).

\section{References}

Avlonitis, G. J., \& Salavou, H. E. (2007). Entrepreneurial orientation of SMEs, product innovativeness, and performance. Journal of Business Research, 60, 5, 566-75.

Barczak, G., Griffin, A. \& Kahn, K. (2009). Perspective: Trends and drivers of success in NPD practices: Results of the 2003 PDMA Best Practices Study. Journal of Product Innovation Management, 26, 1, 3-23.

Barney, J. 1991. Firm resources and sustained competitive advantage. Journal of Management, 17, 1, 99-120.

Colarelli O'Connor, G. \& Rice, M.P. (2013). A comprehensive model of uncertainty associated with radical innovation. Journal of Product Innovation Management, 30, S1, 2-18.

Cuevas-Rodríquez, G., Cabello-Medina, C. \& Carmona-Lavado, A. (2014). Internal and external social capital for radical product innovation: do they always work well together?. British Journal of Management. 25, 266-284.

Danneels, E., \& Kleinschmidt, E. J. (2001). Product innovativeness from the firm's perspective: Its dimensions and their relation with project selection and performance. Journal of Product Innovation Management, 18, 6, 357-73.

Dosi, G. 1982. Technological paradigms and technological trajectories: A suggested interpretation of the determinants and directions of technical change. Research Policy, 11, 3, 147-62.

Eisenhardt, K. M., \& Martin, J.A. (2000). Dynamic capabilities: What are they? Strategic Management Journal, 21, 1105-21.

Garcia, R., \& Calantone, R. (2002). A critical look at technological innovation typology and innovativeness terminology: A literature review. Journal of Product Innovation Management, 19, 2, 110-32.

Griffin, A., Josephson, B.W., Lilien, G., Wiersema, F., Bayus, B., Chandy, R., Dahan, E., Gaskin, S., Kohli, A., Miller, C., Olivia, R., \& Spanjol, J. (2013). Marketing's roles in innovation in business-to-business firms: Status, issues, and research agenda, Marketing Letters, 24,323337.

Holahan, P.J., Sullivan, Z.Z. \& Markham, S.K. (2013). Product development as core competence: How formal product development practices differ for radical, more innovative, and incremental product innovations. Journal of Product Innovation Management, 31, 2, 329-345.

Keupp, M.M. \& Gassmann, O. (2013). Resource constraints as triggers of radical innovation: Longitudinal evidence from the manufacturing sector. Research Policy, 42, 1457-1468.

Kim,W. C., \& Mauborgne, R. (2005). Blue ocean strategy: From theory to practice. California Management Review, 47, 3, 105-21. 
Kindström, D., Kowalkowski, C. \& Sandberg, E. (2013). Enabling service innovation: A dynamic capabilities approach, Journal of Business Research, 66, 8, 1063-1073.

Kock, A., Gemünden, H.G., Salomo, S. \& Schultz, C. (2011). The mixed blessings of technolgocial innovativeness for the commercial success of new products, Journal of Product Innovation Management, 28, S1, 28-43.

Leifer, R., McDermott, C. M., O'Connor, G.C., Peters, L. S., Rice, M. and Veryzer Jr., R. W. (2000). Radical innovation: How mature companies can outsmart upstarts. Cambridge, MA: Harvard Business School Press.

March, J. G. (1991). Exploration and exploitation in organizational learning. Organization Science, 2, 71-87.

Markides, C. (2006). Disruptive innovation: In need of better theory. Journal of Product Innovation Management, 23, 19-25.

Marmer, M., Herrmann, B., Dogrultan, E., Berman, R., Eesley, C., \& Blank, S. (2012). Startup Genome Report Extra Premature Scaling. Startup Genome.

Nicholls-Nixon, C.L., Cooper, A.C., \& Woo, C.Y. (2000). Strategic Experimentation: Understanding change and performance in new ventures, Journal of Business Venturing, 15, 493-521.

Nystrom, P.C. \& Starbuck, W.H. (1984). Organizational façades, Academy of Management, Proceedings of the Annual Meeting, Boston, 182-185.

O'Connor, G. C., \& Ayers, A. D. (2005). Building a radical innovation competency. Research Technology Management, 48, 1, 23-31.

Olson, E., Walker, O. \& Ruekert. R. (1995). Organizing for effective new product development: The moderating role of product innovativeness. Journal of Marketing, 59, 1, 48-62.

Page, A. L., \& Schirr, G. R. (2008). Growth and development of a body of knowledge: Sixteen years of new product development research, 1989-2004. Journal of Product Innovation Management, 5, 3, 233-48.

Prahalad, C. (2004). The blinders of dominant logic. Long Range Planning, 37, 2, 171-179.

Prahalad, C. and Hamel, G. (1990). The core competence of the corporation. Harvard Business Review, 68, 3, 79-87.

Ries, E. (2011). The lean start-up. New York: Crown.

Rubera, G., \& Kirca, A.H. (2012). Firm innovativeness and its performance outcomes: A meta-analytic review and theoretical integration. Journal of Marketing, 76, 2, 130-47.

Schilke, O. (2013). On the contingent value of dynamic capabilities for competitive advantage: The nonlinear moderating effect of environmental dynamism. Strategic Management Journal, 35, 2, 179-203.

Skok D., Why Startups Fail, 2013. Available from http://www.forentrepreneurs.com/business-models/why-startups-fail/ [7 July 2014] 
Slater, S.F., Mohr, J.J. \& Sengupta, S. (2014). Radical Product Innovation Capability: Literature Review, Synthesis, and Illustrative Research Propositions. Journal of Product Innovation Management, 31, 3, 552-566.

Sorescu, A.B., Chandy, R. K. \& Prabhu, J. C. (2003). Sources and Financial Consequences of Radical Innovation: Insights from Pharmaceuticals, Journal of Marketing, 67, 4, pp. 82-102.

Srinivasan, R., Lilien, G. \& Rangaswamy, A. (2002). Technological opportunism and radical technology adoption: An application to e-business. Journal of Marketing, 66, 3, 47-60.

Stam, W., \& Elfring, T., (2008). Entrepreneurial Orientation and new venture performance: The moderating role of intra- and extra-industry social capital. Academy of Management Journal, 51, 1, 97-111.

Story, V., O'Malley, L. \& Hart, S. (2011). Roles, role performance, and radical innovation competences. Industrial Marketing Management, 25, 5-6, 461-481.

Szymanski, D. M., Kroff, M. W. \& Troy, L. C. (2007). Innovativeness and new product success: Insights from the cumulative evidence. Journal of the Academy of Marketing Science, 35, 1, 35-52.

Tajfel, H. \& Turner, J.C. (1986). The social identity theory of intergroup behaviour. In S. Worchel \& W.G. Austin (Eds.), Psychology of Intergroup Relations (7-24). Chicago, IL: NelsonHall.

Teece, D.J. (2007). Explicating dynamic capabilities: The nature and microfoundations of (sustainable) enterprise performance. Strategic Management Journal, 28, 1319-1350.

Tellis, G., Prabhu, J. \& Chandy, R. (2009). Radical innovation across nations: The preeminence of corporate culture. Journal of Marketing, 73, 1, 3-23.

Yadav, M., Prabhu, J. \& Chandy. R. (2007). Managing the future: CEO attention and innovation outcomes. Journal of Marketing, 71, 4, 84-101. 